\title{
Potential biological control of take-all disease in perennial ryegrass
}

\author{
Abdullah Umar ${ }^{1}$, Diwakar R.W. Kandula ${ }^{1 *}$, John G. Hampton ${ }^{1}$, M. Phil Rolston ${ }^{2}$ and Soonie \\ F. $\mathrm{Chng}^{3}$ \\ ${ }^{1}$ Bio-Protection Research Centre, PO Box 85084, Lincoln University, Lincoln 7647, New Zealand \\ ${ }^{2}$ Foundation for Arable Research (FAR), PO Box 32133, Hornby, Christchurch 8441, New \\ Zealand \\ ${ }^{3}$ The New Zealand Institute for Plant and Food Research Limited, Private Bag 4704, \\ Christchurch 8140, New Zealand \\ ${ }^{*}$ Corresponding author: diwakar.kandula@lincoln.ac.nz
}

\begin{abstract}
Perennial ryegrass (Lolium perenne) is the major pasture grass in New Zealand but is highly susceptible to take-all disease, caused by the root-rot pathogen Gaeumannomyces graminis $(G g)$. Isolates of the fungus Trichoderma atroviride are known to control $G g$ but it is not known if a mixture of isolates would be more effective than individual ones. Soil from a field naturally infested with $G g$ was placed in containers in a glasshouse and sown with ryegrass seeds then treated with one of three Trichoderma atroviride isolates or a mixture of all three isolates. All T. atroviride treatments significantly increased shoot dry matter by $46-73 \%$ and root dry matter by $42-62 \%$ compared with the control but a mixture of isolates was no more effective than individual isolates. Application of T. atroviride also significantly decreased root disease severity, which was negatively correlated with root dry matter. Takeall in pastures could possibly be controlled by overdrilling grass with a single isolate of $T$. atroviride.
\end{abstract}

Keywords Gaeumannomyces graminis, Trichoderma atroviride, Lolium perenne

\section{INTRODUCTION}

Perennial ryegrass (Lolium perenne L.) is the most widely sown pasture grass in New Zealand (Charlton \& Stewart, 1999). In an arable cropping rotation, it is often grown after wheat or barley, which are highly susceptible to the soil-borne pathogen Gaeumannomyces graminis $(\mathrm{Gg})$, which causes a disease known as 'take-all' (Cook 2003). Perennial ryegrass is among susceptible hosts of $\mathrm{Gg}$, allowing the carry-over of inoculum between wheat or barley crops and the subsequent grass crop (Bithell et al., 2011a; Chng et al., 2005). This type of rotation, therefore, can lead to the pathogen persisting in soils, and providing inoculum to infect subsequent crops (Bithell et al., 2011b). The symptoms of $G g$ infection of perennial ryegrass are frequently observed above ground and are known as "bare-patch", although other fungal pathogens present may also contribute to these symptoms (Kandula et al. 2014). The infection damages the crop root system and reduces the production of plant dry matter (DM), which may lead to economically important yield losses.

Gaeumannomyces graminis is considered a pathogen that is vulnerable to antagonism not only by other soil microflora in the rhizosphere but also during disease development (Cook 2003). This vulnerability may account for the natural decline of the disease in fields where a build-up of other soil microflora occurs leading to the development of natural antagonism against 
the pathogen. Therefore, application of biological control agents (BCAs) could be an effective tool to control take-all. For instance, Phialophora sp. (isolate I-52) isolated from soil in which takeall had declined (TAD), provided promising take-all control over 5 years of field experiments (Mathre et al., 1999). Also, the presence of diacetylphlorogucinol (DAPG)-producing Pseudomonas fluorescens, at $10^{5}$ to $10^{6}$ colony forming units per gram of roots, in TAD soils was able to suppress take-all (Raaijmakers \& Weller 1998). However, a single species of soil fungus or bacterium may not be sufficient to control diseases in the field, because of the diverse population of soil microorganisms present, and the existence of environmental factors that can significantly affect biocontrol performance and efficacy. For example, Hornby et al. (1998) reported that the overall performance of Pseudomonas and Bacillus species was inconsistent when used for biocontrol of take-all in wheat crops, as only $60 \%$ of biocontrol treatments resulted in significant yield improvement. In addition, the authors noted that these BCAs cannot directly promote plant growth, which is one of the major impediments for production of a successful bacterial biocontrol product

Trichoderma spp. are BCAs that are widely used for controlling a wide range of pathogens and for promoting plant growth in various host plants (Chirino-Valle et al. 2016; Harman et al. 2004; Hicks et al. 2014; Samuels \& Hebbar 2015). The introduction of a BCA into a plant ecosystem can confer benefits to the host, especially in the presence of plant pathogens. In perennial ryegrass, these beneficial effects include (but are not limited to) improvement in seedling emergence and plant DM production (Chohan et al., 2010). The same study demonstrated that the inoculation of four Trichoderma spp. isolates significantly improved perennial ryegrass root and shoot DM production in the presence of the soil-borne pathogen, Rhizoctonia solani. More recently, a pot study by Kandula et al. (2014) demonstrated the potential of Trichoderma spp. in suppressing $G g$. In that study, ryegrass grown in naturally infected soils produced more shoot and root DM when inoculated with Trichoderma spp. compared with the uninoculated control. However, it is generally understood that the performance of the BCAs may be highly variable among seasons and sites, emphasising the need for further studies for their application.

This research complements earlier studies (Kandula et al. 2014; 2015), which showed that T. atroviride isolates LU132, LU140 and LU584 used individually along with other Trichoderma species positively influenced the DM production of ryegrass grown in $\mathrm{Gg}$-infected soils. The present study set out firstly to confirm that $T$. atroviride could provide biocontrol of $G g$, and secondly to test the hypotheses that: (a) a combination of the three T. atroviride isolates will provide a greater reduction in $G g$ root colonisation severity score than any individual isolate, and (b) ryegrass grown in $G g$-infected soil added with the mixture of isolates will produce more DM than those inoculated with any of the isolates added individually.

\section{MATERIALS AND METHODS Experimental site}

The current study, which investigated the effect of T. atroviride on DM production of perennial ryegrass grown in a soil naturally infested with $G g$, was conducted in a glasshouse maintained at an average air temperature of $20 \pm 2^{\circ} \mathrm{C}$ from April to September 2018 at Lincoln University, Canterbury.

\section{Experimental design}

The experiment consisted of five treatments ( $T$. atroviride isolates LU132, LU140, LU584 from the Bio-Protection Research Centre's 'Trichobank', a mixture of these isolates, and an uninoculated control), with each treatment replicated eight times to give a total of 40 containers. Containers were arranged in a randomised complete block design.

\section{Seed lot}

The seed lot was perennial ryegrass cv 'Grasslands Nui' provided by the Foundation for Arable Research. The seed lot had a germination of $96 \%$ (R. Chynoweth, FAR, pers. comm). 


\section{Inverted sward technique}

The soil used in the experiment was collected from a farm in the Greendale-Darfield area, Selwyn District, Canterbury, in April 2018. The soil was from a field previously used to grow a ryegrass seed crop where symptoms of takeall (dead seed heads and very small ryegrass seed) had been reported. The soil was prepared as a growth medium using an inverted sward technique described by Kandula et al. (2014). Square-shaped swards (size $20 \times 20 \times 5 \mathrm{~cm}$ ) were taken from random locations within a perennial ryegrass-based pasture. Soil blocks were cut using a spade and then inverted before being placed into each of 40 two-litre ice cream containers. Additional soil was also collected and added to each of the containers to ensure each container contained $2 \mathrm{~L}$ of soil.

The soil in each container was sown with 48 untreated perennial ryegrass seeds arranged in three rows (16 seeds/row). Then, formulated prills (of proprietary composition provided by Agrimm Technologies Ltd., Lincoln) containing $10^{7}$ colony forming units (CFUs)/g prill) of the T. atroviride isolates (for the mixture, one third of each isolate was used) were spread in the sowing grooves, while blank prills were used as the control treatment $(1 \mathrm{~g} /$ container which was equivalent to $15 \mathrm{~kg} / \mathrm{ha}$ ). After that, about $30 \mathrm{~g}$ of potting mix per container was lightly distributed on the surface of the growth medium to cover the sown seeds and provide additional nutrients for the plants. The potting mix comprised bark and pumice in a ratio of $4: 1(\mathrm{v} / \mathrm{v})$ enriched with Osmocote Exact fertiliser 16-3-9-10 (3-4 months) (ICL Specialty Fertilizers, NSW, Australia), horticultural lime and Hydraflo-2 granular wetting agent (Everris Australia Pty Ltd., NSW, Australia) in a ratio of 3:1:1 (v/v/v). The containers (10 replicates per treatment) were placed in a random design in the glasshouse, and watered once every day to provide favourable conditions for plants and soil microflora.

\section{Assessments}

Seedling emergence was recorded at 7, 9, and 39 days after sowing (DAS). The results are presented as a percentage of the sown seeds.

Shoot dry weight was measured three times at 52-day intervals by cutting the plants at $3 \mathrm{~cm}$ above the soil surface and drying the shoots at $65^{\circ} \mathrm{C}$ in a forced-draft oven for $48 \mathrm{~h}$. After the third harvest, plant roots were collected, washed thoroughly free of soil and dried at $65^{\circ} \mathrm{C}$ for $96 \mathrm{~h}$ to obtain the root dry weight.

Roots were assessed microscopically for the presence of $G g$ runner hyphae and/or hyphodia. Root disease severity was scored based on root deterioration due to rotting and pathogen colonisation using the following scale:

$$
\begin{aligned}
0= & \text { root intact and no runner hyphae } \\
1= & \text { root intact with runner hyphae on some } \\
& \text { roots } \\
2= & \text { root intact with runner hyphae on most } \\
& \text { roots } \\
3= & \text { disintegrated root with hyphae on all the } \\
& \text { roots and hyphodia on some roots } \\
4= & \text { disintegrated root with hyphae and } \\
& \text { hyphodia on most roots } \\
5= & \text { totally disintegrated root with hyphae and } \\
& \text { hyphodia on all the roots. }
\end{aligned}
$$

\section{Statistical analysis}

Data were analysed using an analysis of variance (ANOVA) with T. atroviride as the only factor in the treatment structure. Seedling emergence was analysed using data collected at 7 and 9 DAS. The number of seedlings were accumulated until 39 DAS to observe the maximum number that emerged in each container, then analysed and presented as the final percentage seedling emergence for each treatment.

The least significant difference (LSD) test at $\mathrm{P}<0.05$ was used to further investigate the difference of mean value between treatments. All data (no transformations were necessary) analyses were carried out using Genstat software (18th edition, VSN International, Hemel Hempstead, UK).

\section{RESULTS}

No significant differences were found in the percentage seedling emergence of ryegrass 
between each of the three individual $T$. atroviride isolates and control plants at the first (mean 60\%) and second counts (mean 84\%) or for the final emergence (Table 1). In contrast, the mixture of all three isolates significantly $(\mathrm{P}<0.05)$ increased the final emergence compared with that of the untreated control (Table 1).

Overall, perennial ryegrass treated with $T$. atroviride isolates produced higher shoot dry matter (SDM) than the control plants (Table 1). At 52 DAS, isolate LU132 had significantly $(\mathrm{P}<0.05)$ increased the SDM by $61 \%$ (Fig. 1). At 104 DAS, cumulative SDM did not differ significantly among treatments (Fig. 1). However, at 156 DAS, plants grown in association with $T$. atroviride isolates LU132, LU140, LU584, either applied on their own or as a mixture, had produced a significantly $(\mathrm{P}<0.05)$ greater cumulative SDM than the control (Table 1; Fig. 1) with increases of $73 \%, 66 \%, 46 \%$, and $68 \%$, respectively.

Application of T. atroviride increased root dry matter (RDM) but differences were significant $(\mathrm{P}<0.05)$ only in plants treated with LU140 or the mixture of isolates (Table 1), with increases of $60 \%$ and $62 \%$, respectively, over that of untreated plants. Isolates LU132 and LU584 increased
RDM by $44 \%$ and $42 \%$, respectively, but these increases were not significant. There was a positive correlation between increased RDM and cumulative shoot dry matter (Fig. 2).

Root infection by $G g$ was confirmed by the presence of the 'runner hyphae' and hyphodia of the pathogen by visual assessment under a microscope (Fig. 3). Application of individual T. atroviride isolates or a mixture of these significantly $(\mathrm{P}<0.05)$ reduced the root disease severity of treated grass seedlings. Untreated control plants had a root-disease score of 3.0 but this score decreased to $1.0,1.0,1.8$, and 1.1 for seedlings treated with $T$. atroviride isolates LU132, LU140, LU584, and the mixture of these isolates, respectively (Table 1). Isolate LU584 was the least effective in protecting ryegrass from $G g$ infection as indicated by the lowest cumulative shoot dry weight $(9.17 \mathrm{~g})$ and root dry weight $(9.60 \mathrm{~g})$, and the highest disease score (1.75) (Table 1). Root disease severity, SDM and RDM in grass treated with the mixture of isolates did not differ from that of the individual isolates. The root disease score was negatively correlated with the RDM (Fig. 4).

Table 1 Effect of Trichoderma atroviride isolates on final seedling emergence, cumulative shoot dry matter, root dry matter, and root disease severity score of perennial ryegrass grown in a Gaeumannomyces graminis infected soil.

\begin{tabular}{lcccc}
\hline $\begin{array}{l}\text { Trichoderma } \\
\text { atroviride isolate }\end{array}$ & $\begin{array}{l}\text { Final seedling } \\
\text { emergence }(\%) \\
\text { at 39 DAS }\end{array}$ & $\begin{array}{l}\text { Cumulative } \\
\text { shoot dry } \\
\text { matter (g) } \\
\text { at 156 DAS }\end{array}$ & $\begin{array}{l}\text { Root dry } \\
\text { matter (g) } \\
\text { at 156 DAS }\end{array}$ & $\begin{array}{l}\text { Root disease } \\
\text { severity score }\end{array}$ \\
\hline None (control) & 85.7 & 6.29 & 6.76 & 3.00 \\
LU132 & 88.0 & $10.88^{*}$ & 9.75 & $1.00^{*}$ \\
LU140 & 89.8 & $10.42^{*}$ & $10.80^{*}$ & $1.00^{*}$ \\
LU584 & 88.3 & $9.17^{\star}$ & 9.60 & $1.75^{\star}$ \\
LU132+ LU140+ LU584 & $92.4^{*}$ & $10.55^{\star}$ & $10.97^{\star}$ & $1.13^{\star}$ \\
SED & 2.7 & 0.81 & 1.48 & 0.34 \\
\hline LSD (5\%) & 5.6 & 1.66 & 3.03 & 0.69 \\
\hline
\end{tabular}

28 residual degrees of freedom for all variables; ${ }^{\star}$ indicates $5 \%$ significant difference from control plants in the same column.

${ }^{\mathrm{a}} \mathrm{DAS}=$ days after sowing; ${ }^{\mathrm{b}}=$ grams per container. 


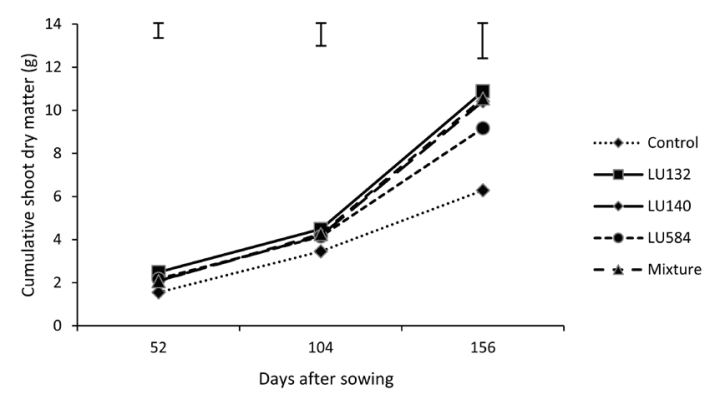

Figure 1 Cumulative shoot dry matter of perennial ryegrass grown in a Gaeumannomyces graminis-infected soil treated with different Trichoderma atroviride isolates. Error bars are the least significant difference (LSD) at the 5\% level.

\section{DISCUSSION}

The purpose of this study was firstly to confirm that T. atroviride could provide biocontrol of $G g$, and secondly to test the hypothesis that the mixture of isolates could deliver better biocontrol efficacy than any individual isolate in perennial ryegrass grown in a soil naturally infected with $G g$ and also that ryegrass would grow better with the BCA. The presence of $G g$ in this soil was confirmed microscopically during the root disease assessment, showing the characteristic 'runner hyphae' and hyphodia of $G g$ developed in the ryegrass roots.

Overall, the results demonstrated biocontrol of $G g$, but did not support the hypothesis that a combination of T. atroviride isolates can improve

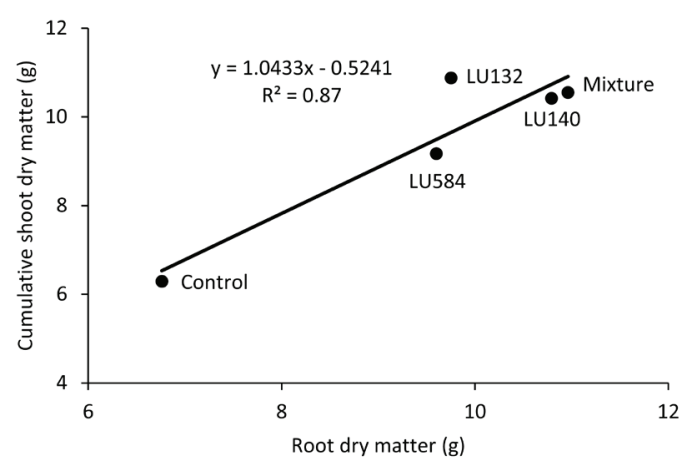

Figure 2 Cumulative shoot dry matter (measured on 52, 104 and 156 days after sowing (DAS)) and final root dry matter (156 DAS) of perennial ryegrass grown in a Gaeumannomyces graminisinfected soil treated with different Trichoderma atroviride isolates; correlation co-efficient, $\mathrm{r}=$ 0.93 .

biocontrol efficacy and increase the consistency of growth promotion over that of individual isolates (Harman et al. 2004; Stewart \& Hill 2014). The efficacy of the mixture of isolates was only as good as the individual isolates in increasing SDM and reducing $G g$ colonisation. However, only the mixture of isolates and LU140 produced a greater RDM than the control. This mixture was also the only treatment that significantly increased the RDM of prairie grass (Bromus willdenowii) grown in soil containing $G g$ in a separate study (Umar, 2018). A greater root development will have a significant impact on the capacity of plants to take up water and minerals (Marzec et
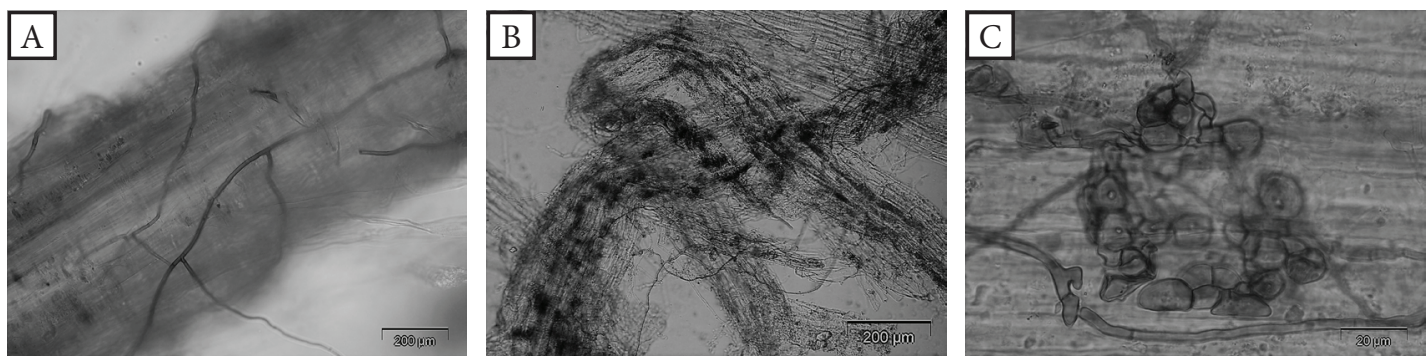

Figure 3 Photomicrographs of perennial ryegrass roots infected with Gaeumannomyces graminis. A. Root with few runner hyphae; B. Root heavily infected with runner hyphae and hyphodia; C. Close-up of runner hyphae and clusters of hyphodia. 


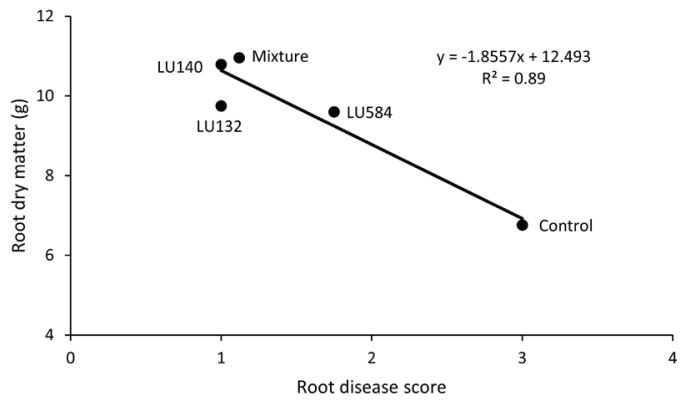

Figure 4 Root disease score and root dry matter of perennial ryegrass grown in a Gaeumannomyces graminis-infected soil treated with different Trichoderma atroviride isolates; correlation coefficient, $r=0.94$.

al. 2015). Additionally, deeper roots could benefit soil structure by increasing its steady-state carbon, water and nutrient retention, leading to more sustainable plant yields (Kell 2011). The mixture of isolates might, therefore, have the potential to better prepare the plant to cope with environmental stress (Harman et al. 2004; Umar 2018). Multiple strains can exhibit different or complementary modes of action to colonise the root microsystem (Whipps 2001), and deliver a broader spectrum of biocontrol activity (Stewart \& Hill 2014).

All T. atroviride treatments significantly increased the production of SDM by 156 DAS. These results are in agreement with those obtained by Kandula et al. (2014) who reported an increase of cumulative SDM of $G g$-infected ryegrass treated with $T$. atroviride isolates (same as in this study) 215 DAS, compared to untreated plants. These results also support earlier studies that showed Trichoderma spp. promoted growth in pasture species (Kandula et al. 2015).

The T. atroviride isolates used in the current study effectively reduced root disease severity, most probably by colonising the plant root system and thus subsequently reducing $G g$ infection. Trichoderma atroviride isolates are known to be rhizosphere-competent strains (Cripps-Guazzone, 2014; Kandula et al., 2015). A rhizosphere-competent strain of Trichoderma spp. can colonise the root externally and internally and subsequently establish a zone of interaction into which it releases bioactive molecules (Harman et al. 2004). Such molecules include elicitors of resistance or enzymes that enhance plant resistance. Moreover, Trichoderma spp. strains can directly attack the pathogen by producing enzymes that can release cellwall fragments from the hyphae of the target pathogen. It has also been reported that $T$. harzianum and T. koningii produce antibiotics to attack $G g$ (Hornby et al. 1998). Trichoderma spp. may also suppress the pathogen through parasitism in which the biocontrol fungus coils around the pathogen hyphae and produces a number of synergistic cell-wall-degrading enzymes, which eventually cause infection and death of the pathogen (Harman et al. 2004).

The reduction of root disease severity resulted in increases in root dry weight ranging from 42 to $62 \%$ (Fig. 4). This increased root mass may be attributed to both direct suppression of $\mathrm{Gg}$ by $\mathrm{T}$. atroviride isolates, as indicated by lower disease scores, and growth promotion. Trichoderma atroviride isolates LU132, LU140 and LU584 have been reported previously to increase perennial ryegrass root weight (by 24 to $100 \%$ ) in the absence of pathogen infection (Kandula et al. 2015), demonstrating the ability of these isolates to promote plant growth directly in a grass crop. However, whether the increase in root mass resulted from disease control or growth promotion, or a combination of both could not be determined in this study.

\section{CONCLUSIONS}

Gaeumannomyces graminis infection of perennial ryegrass roots significantly reduced plant root and shoot DM in a glasshouse experiment. Application of three individual $T$. atroviride isolates and a mixture of the three reduced $G g$ root disease score and resulted in large increases in both root and shoot dry weight. The negative impact of $G g$ infection on pasture production, and also possibly grass seed production, could be alleviated by overdrilling Trichoderma prills into existing pasture, or applying a Trichoderma 
seed coating for new sowings. This approach is being investigated with field experiments in the 2019/20 season.

\section{ACKNOWLEDGEMENTS}

The authors thank Hamish Redfern, Greendale for allowing access to his field for collection of the swards, and Murray Kelly, PGGWrightson Seeds, Kimihia who arranged the contact. Thanks to Agrimm Technologies Ltd., Lincoln, Canterbury for supplying the formulations. Addullah Umar also thanks the Indonesian Agency for Agricultural Research and Development who provided the scholarship which funded his Masterate study.

\section{REFERENCES}

Bithell SL, Butler RC, Harrow S, McKay A, Cromey MG 2011a. Susceptibility to take-all of cereal and grass species, and their effects on pathogen inoculum. Annals of Applied Biology 159: 252-266.

Bithell SL, Butler RC, McKay A, Cromey MG 2011 b. Wheat volunteers in Lolium perenne - effects on Gaeumannomyces graminis var. tritici carry-over and take-all. New Zealand Plant Protection 64: 175-182.

Charlton JFL, Stewart AV 1999. Pasture species and cultivars used in New Zealand - a list. Proceedings of the New Zealand Grassland Association 61: 147-166.

Chirino-Valle I, Kandula D, Littlejohn C, Hill $\mathrm{R}$, Walker $\mathrm{M}$, Shields $\mathrm{M}$, Cummings $\mathrm{N}$, Hettiarachchi D, Wratten S. 2016. Potential of the beneficial fungus Trichoderma to enhance ecosystem-service provision in the biofuel grass Miscanthus x giganteus in agriculture. Scientific Reports 6, e25109.

Chng SF, Cromey MG, Butler RC 2005. Evaluation of the susceptibility of various grass species to Gaeumannomyces graminis var. tritici. New Zealand Plant Protection 58: 261-267.

Chohan PK, Kandula DRW, Stewart A, Hampton JG 2010. Biological control of Rhizoctonia solani in perennial ryegrass using Trichoderma atroviride isolates. Presented at the $6^{\text {th }}$ Australasian soilborne diseases symposium, Queensland, Australia, 9-11 August.

Cook RJ 2003. Take-all of wheat. Physiological and Molecular Plant Pathology 62: 73-86.

Cripps-Guazzone N 2014. Rhizosphere competence of selected Trichoderma species (Unpublished $\mathrm{PhD}$ Thesis). Lincoln University, New Zealand.

Harman GE, Howell CR, Viterbo A, Ilan C, Lorito M 2004. Trichoderma species - opportunistic, avirulent plant symbionts. Nature ReviewsMicrobiology 2: 43-56.

Hicks E, Bienkowski D, Braithwaite M, McLean K, Falloon R, Stewart A 2014. Trichoderma strains suppress Rhizoctonia diseases and promote growth of potato. Phytopathologia Mediterranea 53: 502-514.

Hornby D, Bateman GL, Gutteridge RJ, Ward E, Yarham DJ 1998. Take-All disease of cereals: A regional perspective. CAB International, UK.

Kandula DRW, Jones EE, Stewart A, McLean KL, Hampton JG 2015. Trichoderma species for biocontrol of soil-borne plant pathogens of pasture species. Biocontrol Science and Technology 25: 1052-1069.

Kandula DRW, Stewart A, Duerr, E, Hampton JG, Gale D 2014. Biological control of pasture bare-patch disease with Trichoderma bioinoculant. Presented at the $8^{\text {th }}$ Australasian Soilborne Diseases Symposium, Hobart, Australia, 10-13 November.

Kell DB 2011. Breeding crop plants with deep roots: their role in sustainable carbon, nutrient and water sequestration. Annals of Botany 108: 407-418.

Marzec M, Melzer M, Szarejko I 2015. Root hair development in the grasses: what we already know and what we still need to know. Plant Physiology 168: 407-414.

Mathre DE, Cook RJ, Callan NW 1999. From discovery to use: Traversing the world of commercializing biocontrol agents for plant disease control. Plant Disease 83: 972-983.

Raaijmakers JM, Weller DM 1998. Natural plant protection by 2,4-diacetylphloroglucinolproducing Pseudomonas spp. in take-all decline soils. Molecular Plant-Microbe 
Interactions 11:144-152.

Samuels GJ, Hebbar PK 2015. Trichodermaidentification and agricultural applications. APS Press, The American Phytopathological Society, St. Paul, MN, USA.

Stewart A, Hill R 2014. Applications of Trichoderma in plant growth promotion. In: Gupta VK, Schmoll M, Herrera-Estrella A, Upadhyay RS Druzhinina I, Tuohy MG Eds, Biotechnology and Biology of Trichoderma. Elsevier, The Netherlands. Pp. 415-428.

Whipps JM 2001. Microbial interactions and biocontrol in the rhizosphere. Journal of Experimental Botany 52: 487-511.

Umar A 2019. Studies on the efficacy of three Trichoderma atroviride isolates for controlling take-all (Gaeumannomyces graminis var. tritici) in grasses. A thesis submitted in partial fulfilment of the requirements for the Degree of Master of Science, Lincoln University, New Zealand. 